\title{
Photovoltaic and Thermal Hybridized Solar Cooker
}

\author{
Smita B. Joshi and A. R. Jani \\ Department of Physics, Sardar Patel University, Vallabh Vidyanagar, Gujarat 388120, India \\ Correspondence should be addressed to A. R. Jani; janiar@rediffmail.com
}

Received 22 April 2013; Accepted 12 May 2013

Academic Editors: E. R. Bandala and V. Makareviciene

Copyright (C) 2013 S. B. Joshi and A. R. Jani. This is an open access article distributed under the Creative Commons Attribution License, which permits unrestricted use, distribution, and reproduction in any medium, provided the original work is properly cited.

\begin{abstract}
The objective of the present research work is to design user friendly solar cooker which can be commercialized too. This cooker is designed, developed, and tested in our laboratory. The basic principle is to incorporate heating into material by photovoltaic effect and thermal treatment. Different temperatures inside the solar cooker were measured and profile of solar cooker was studied for several days during April, May, and June 2012. It is observed that the designed cooker needs the boosting of only 30 watt power which is generated by a small solar panel connected with it. Heater connected with it can be powered by a solar panel of 75 watt. This boosting can reduce the cooking time. Different recipes were prepared to test its actual performance.
\end{abstract}

\section{Introduction}

Food is one of the basic needs like water and air. Food preparation requires a fuel which may be wood, coal, cow dung, liquid petroleum gas, and electricity consuming induction heaters or microwave. Availability of these nonrenewable sources is a burning task. Moreover, it produces pollution which leads to imbalance in the nature. Solar cooker either box type or concentrating type can be one of the solutions of this critical problem. The solar cookers available in national and international market are not as popular as they should be. The objective of our research is to design user-friendly solar cooker which can cook a little faster than the conventional box type solar cooker for more than 300 days per year. The electrically boosted heater has made it 24 hours usable cooker.

\section{Materials and Methods}

Figure 1 shows the schematic diagram of Photo-Thermo solar cooker. Photo-Thermo solar cooker was constructed using a stainless steel casserole and a DC heater. The heater was fixed inside the casserole with screws. Stainless still pot was used for cooking in the casserole while aluminum pots were used in Star and GEDA cookers.
The Photo-Thermo solar cooker is a photovoltaic and thermal hybridized solar cooker. It is connected to a 12 volt 40 ampere-hour battery. This battery will be charged by a solar panel of 75 watt. To decide the minimum requirement of wattage for cooking, we operated the cooker with a power supply. This testing was indoor testing under all controlled parameters like wind, ambient temperatures, and humidity, and so forth. The insolation and ambient temperature data were given by Sardar Patel Renewable Energy Institute, SPRERI, situated at Gujarat, India. Horizontal insolation was recorded by pyranometer with $\pm 2 \%$ accuracy. Thermal sensor for ambient temperature and calibrated J-type thermocouples made of copper constantan were used to measure temperatures at different state points attached with data logger DT600 Series 3.

Before designing the Photo-Thermo solar cooker, we studied the temperature profile of Star cooker and Gujarat Energy Development Agency (GEDA) cooker in the month of May when insolation was sufficient for cooking. To study the temperature profile of solar cookers, Pt-100 sensors were mounted in different places like upper glass, lower glass, collector plate, hot air inside cooker, insulation, cooking pot, and so forth. Table 1 shows the dimensions of the entire three cookers GEDA cooker, Star solar cooker, and Photo-Thermo solar cooker. 
TABLE 1: Dimensions of solar cookers.

\begin{tabular}{|c|c|c|c|}
\hline Cooker parameters & $\begin{array}{l}\text { Aluminum body } \\
\text { cooker (GEDA) }\end{array}$ & $\begin{array}{l}\text { Aluminum body } \\
\text { star solar cooker }\end{array}$ & $\begin{array}{c}\text { Stainless steel } \\
\text { Photo-Thermo solar } \\
\text { cooker }\end{array}$ \\
\hline Weight (kg) & 12.3 & 4.8 & 1.6 \\
\hline \multirow{2}{*}{ Volume $\left(\mathrm{m}^{3}\right)$} & $l \times b \times h$ & $l \times b \times h$ & Outer diameter $0.25 \mathrm{~m}$ \\
\hline & $0.52 \times 0.52 \times 0.20$ & $0.30 \times 0.30 \times 0.15$ & Flat height $0.09 \mathrm{~m}$ \\
\hline \multirow{2}{*}{ Dimension of cavity $\left(\mathrm{m}^{3}\right)$} & $0.43 * 0.43$ & $0.23 * 0.23$ & Inner diameter $0.23 \mathrm{~m}$ \\
\hline & Depth 0.078 & Depth 0.07 & Depth: $0.085 \mathrm{~m}$ \\
\hline \multirow{3}{*}{ Number of pots with size of each one (m) } & Four & One & One \\
\hline & Diameter 0.19 & Diameter 0.19 & Diameter 0.17 \\
\hline & Height 0.065 & Height 0.065 & Height 0.05 \\
\hline Black absorber paint & Black board paint & Black board paint & Not needed \\
\hline \multirow{3}{*}{ Insulation (m) } & Glass wool & Glass wool & Puff \\
\hline & Side 0.043 & Side 0.02 & 0.025 \\
\hline & Bottom 0.049 & Bottom 0.04 & \\
\hline Number of glass covers (glazing) & Two & Two & Not needed \\
\hline Size of the reflecting mirror $\left(\mathrm{m}^{2}\right)$ & $0.46 * 0.46$ & $0.26 * 0.26$ & Not needed \\
\hline Heater (m) & - & - & $\begin{array}{l}\text { Diameter: } 0.15 \\
\text { Thickness: } 0.04\end{array}$ \\
\hline
\end{tabular}

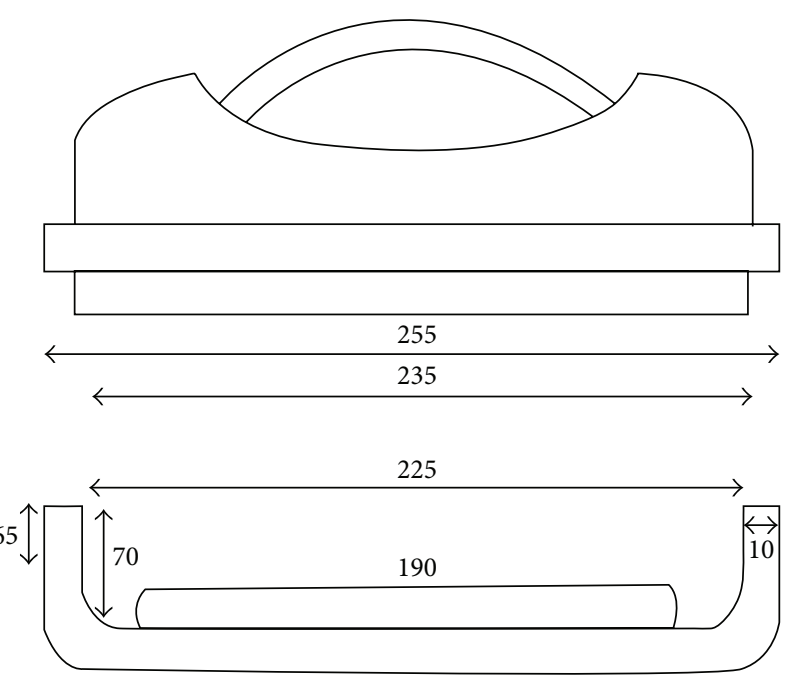

FIGURE 1: Schematic diagram of Photo-Thermo solar cooker.

\section{Results}

Figure 2 shows the graph for temperature profile of Star solar cooker loaded with 1 litre of tap water. Figure 3 shows the temperature profile of Star solar cooker and GEDA cooker. Both the cookers were kept empty so that their figure of merit F1 can be calculated for the comparison of their performance. The cookers were installed due south and the mirror was covered with black cotton cloth.

Figure 4 shows the graph for the hard nuts cooking. Different recipes like rice, pulses, vegetables, and cake were cooked in solar cooker.

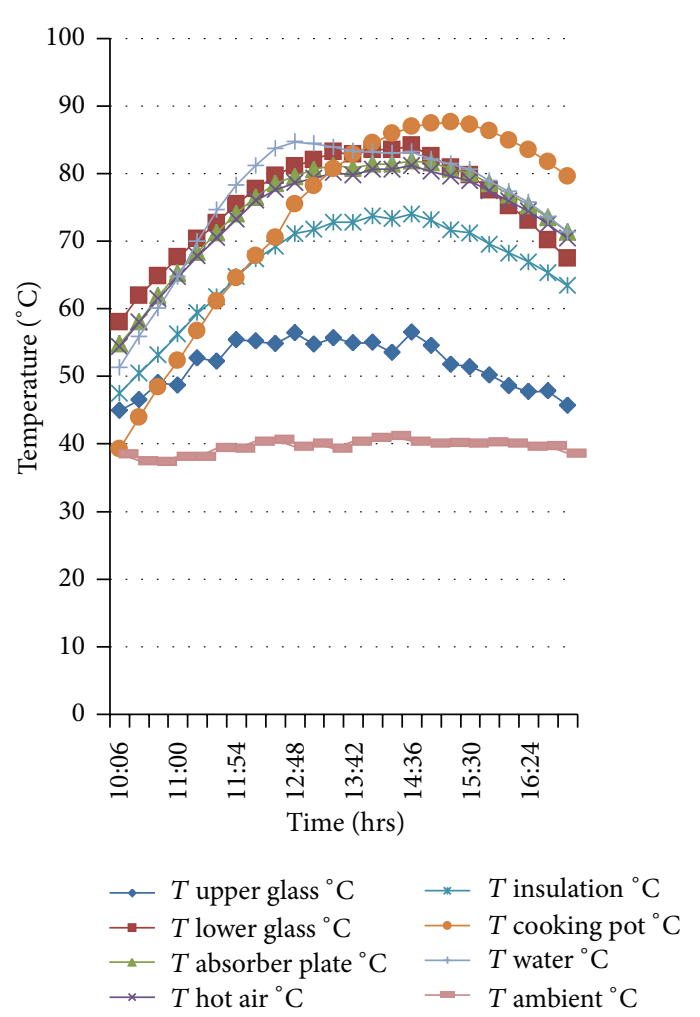

FIgURE 2: Temperature profile of the Star solar cooker.

Figure 5 shows the insolation and ambient temperature data given by SPRERI. It shows a typical insolation curve of 4, 8 and 11 May 2012. 8th May was the clear sunny day. The peak of insolation was about 836 watt/meter ${ }^{2}$ and then it 


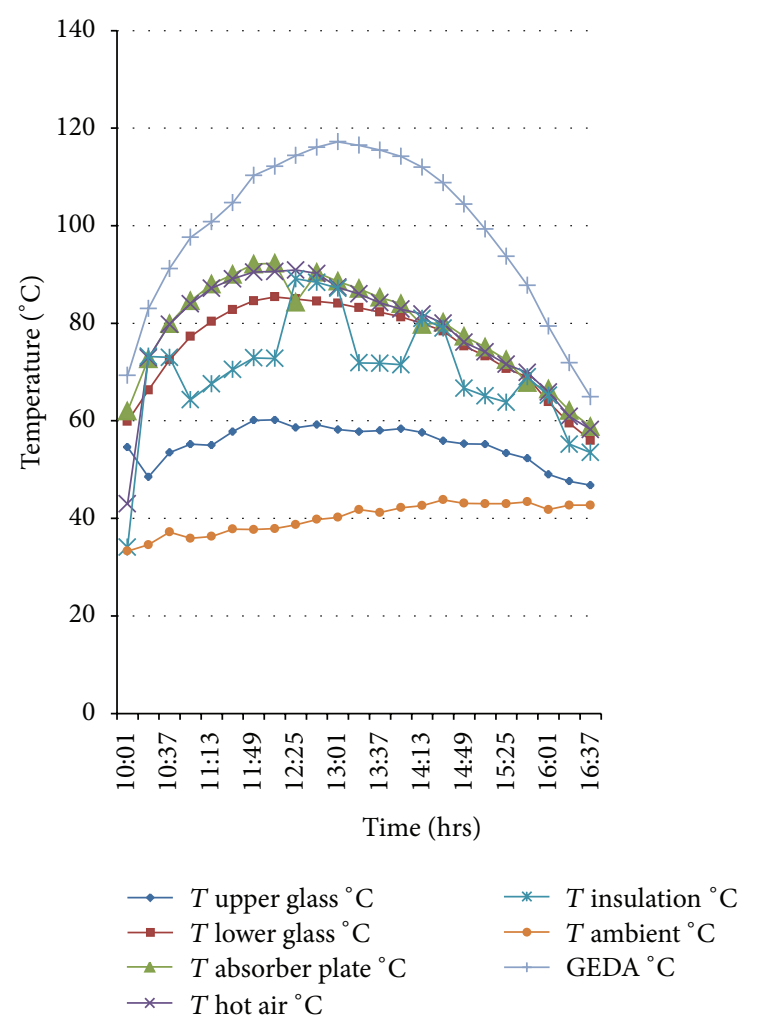

FIgURE 3: Temperature profile for Star and GEDA cookers.

started decreasing gradually as it is expected. The maximum temperature recorded for GEDA cooker and Star Cooker was $122.6^{\circ} \mathrm{C}$ and $85.7^{\circ} \mathrm{C}$, respectively. Figure 6 shows time versus temperature plot for water heating in Photo-Thermo solar cooker. The temperatures of heater, water, and the lid of the pot were measured by an interval of 10 minutes with Pt-100 thermocouples and temperature indicator.

Figure 7 shows the graph of rice cooking in PhotoThermo solar cooker. The power supply was switched off at 12 O'clock, that is, after 100 minutes. Table 2 shows the readings for the same cooker for water heating test.

\section{Discussions}

The international standard for testing solar cookers decided by BIS convened at Coimbatore on 9 January 1997, suggested that effective cooking power, which accounts for both different cooker sizes and heat gain rates, should be performed. The influence test conditions of results can be minimized if uncontrolled variables like wind, ambient temperature, pot contents temperature, insolation, solar altitude, and azimuth angle are held within certain ranges. Therefore, the committee recommends the following test procedure $[1,2]$.

\subsection{Uncontrolled (Weather) Variables}

4.1.1. Wind Velocities. Wind velocities less than $1.0 \mathrm{~m} / \mathrm{s}$ help to maintain a heat loss coefficient close to the natural convection loss, making tests more consistent and repeatable. If wind

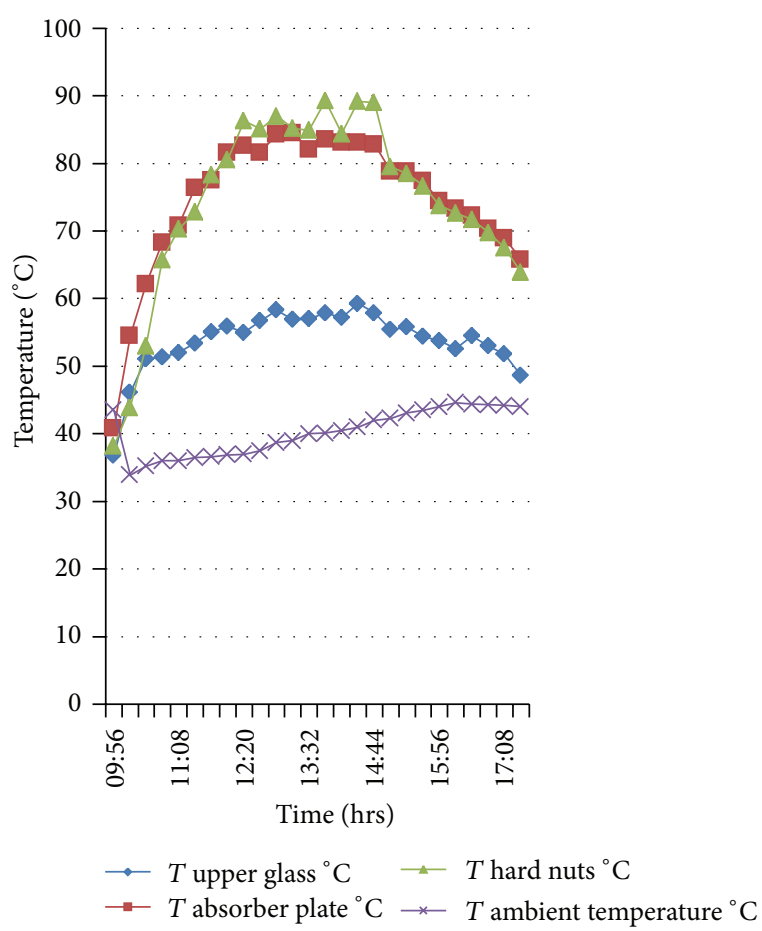

Figure 4: Temperature profile of Star cooker.

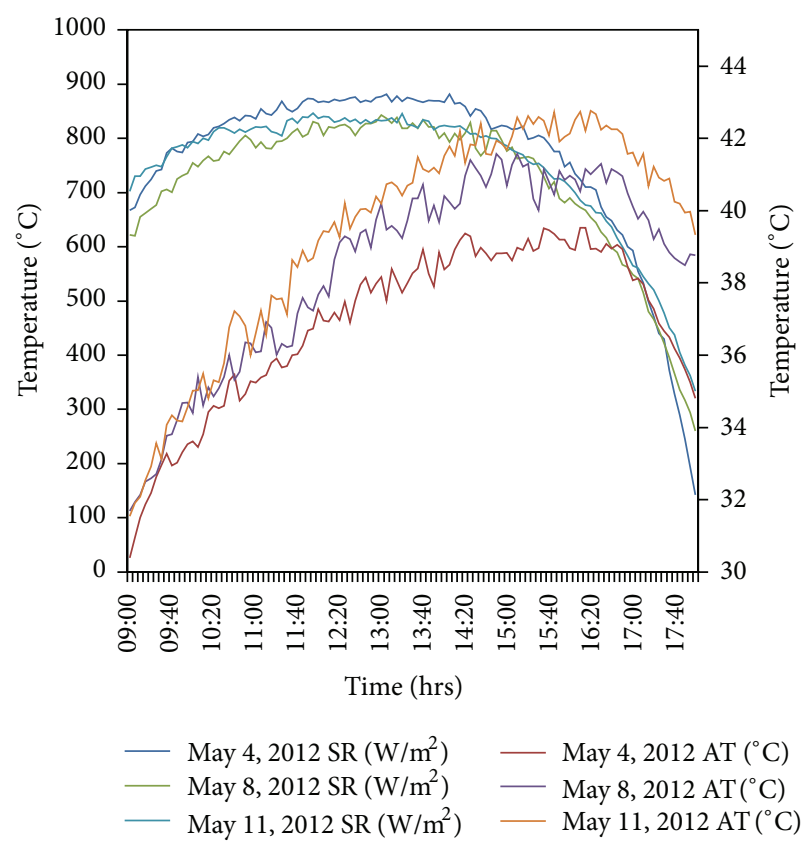

FIGURE 5: Insolation and ambient temperature data.

shelter is required, it must be constructed so that it does not interfere with incoming total radiation. The parameter Wind does not affect in designing solar cooker as the cooking is done in the kitchen which serves better than a wind shelter.

4.1.2. Ambient Temperature. Conduct solar cooker tests when ambient temperatures are between $20^{\circ} \mathrm{C}$ and $35^{\circ} \mathrm{C}$ because 


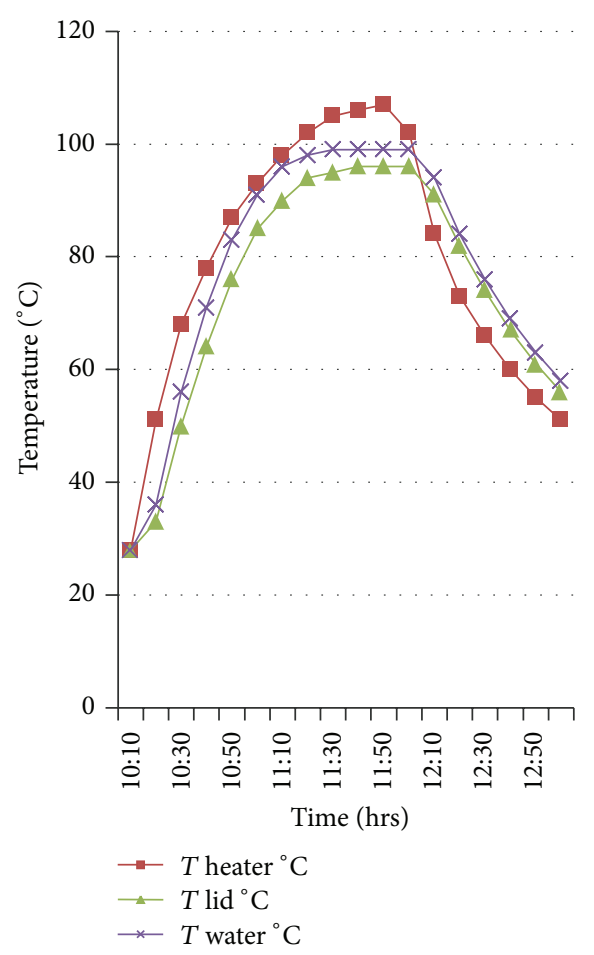

Figure 6: Time versus temperature plot of Photo-Thermo solar cooker.

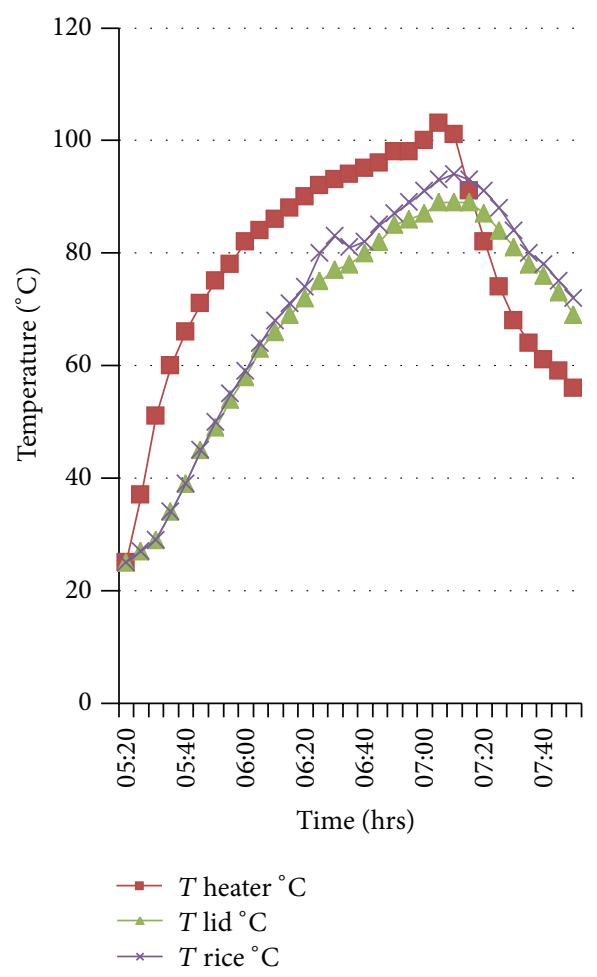

FIgURE 7: Time versus temperature plot for rice cooking in PhotoThermo solar cooker.
TABle 2: Water heating in Photo-Thermo solar cooker.

\begin{tabular}{lcccc}
\hline Time hrs & $\begin{array}{c}\text { Time } \\
\text { minute }\end{array}$ & $\begin{array}{c}\text { Heater temp. } \\
{ }^{\circ} \mathrm{C}\end{array}$ & $\begin{array}{c}\text { Water temp. } \\
{ }^{\circ} \mathrm{C}\end{array}$ & $\begin{array}{c}\text { Lid temp. } \\
{ }^{\circ} \mathrm{C}\end{array}$ \\
\hline $10: 10$ & 0 & 28 & 28 & 28 \\
$10: 20$ & 10 & 51 & 36 & 33 \\
$10: 30$ & 20 & 68 & 56 & 50 \\
$10: 40$ & 30 & 78 & 71 & 64 \\
$10: 50$ & 40 & 87 & 83 & 76 \\
$11: 00$ & 50 & 93 & 91 & 85 \\
$11: 10$ & 60 & 98 & 96 & 90 \\
$11: 20$ & 70 & 102 & 98 & 94 \\
$11: 30$ & 80 & 105 & 99 & 95 \\
$11: 40$ & 90 & 106 & 99 & 96 \\
$11: 50$ & 100 & 107 & 99 & 96 \\
$12: 00$ & 110 & 102 & 99 & 96 \\
$12: 10$ & 120 & 84 & 94 & 91 \\
$12: 20$ & 130 & 73 & 84 & 82 \\
$12: 30$ & 140 & 66 & 76 & 74 \\
$12: 40$ & 150 & 60 & 69 & 67 \\
$12: 50$ & 160 & 55 & 63 & 61 \\
$13: 00$ & 170 & 51 & 58 & 56 \\
\hline
\end{tabular}

cooking power is influenced by temperature difference. A range of $15^{\circ} \mathrm{C}$ keeps variability moderate. In the designed cooker, the indoor cooking temperature change is less than $5^{\circ} \mathrm{C}$ so the above parameter becomes partially controlled parameter.

4.1.3. Pot Contents Temperature. Record the data for water temperatures between $40^{\circ} \mathrm{C}$ and $90^{\circ} \mathrm{C}$ because pot contents must be above ambient temperature for compensating heat losses. The latent heat of vaporization severely depresses apparent cooking power as the water near boiling point. There is less possibility in fall of pot content temperatures as it depends on the above two parameters, namely, wind and ambient temperature which are least concerned with indoor cooking.

4.1.4. Insolation. Available solar energy is to be measured in the plane perpendicular to direct beam radiation (the maximum reading) using a radiation pyranometer. Variation in measured insolation greater than $100 \mathrm{watt} / \mathrm{meter}^{2}$ during a ten-minute interval or readings below $450 \mathrm{watt} / \mathrm{meter}^{2}$ or above 1100 watt $/$ meter $^{2}$ during the test render the test invalid. In designing cooker, the battery is already charged with a solar penal. So any change in insolation with time hardly matters.

4.1.5. Solar Altitude and Azimuth Angle. Tests are to be conducted between 10:00 hrs and 14:00 hrs solar time, because solar zenith angle is somewhat constant at midday, and the difference between the insolation perpendicular to direct beam radiation will be very less. 
This parameter does not affect the performance of designed solar cooker as this battery operated cooker can cook round the clock as per the requirement of the user.

4.2. Controlled Variables. The controlled parameters of solar cooker are loading and tracking.

4.2.1. Loading. Water closely resembles food in density and specific heat but is more consistent. Intercepted radiation is the best measure of available energy. Thermal performance is sensitive to loading rate.

The designed cooker was tested with and without load. As it is merely a prototype of cooker, the load was limited to $100 \mathrm{~mL}$ and the test was repeated for several times for confirmation of the load. Intercept area and beam radiation zenith angle do not play any role here as the reflector is not needed and the system is closed by an opaque cover.

4.2.2. Tracking. Azimuth angle tracking frequency must be appropriate to the cooker's acceptance angle. Box-type cookers typically require adjustment every 15 to 30 minutes or when shadows appear on the absorber plate. With box-type cookers, zenith angle tracking may be unnecessary during a two-hour test conducted at midday.

The cooker needs no tracking as it is used in kitchen only. It does not need focusing as the cooking is done with a battery charged by a solar panel. Particularly, midday cooking is not a compulsion in our designed cooker.

4.2.3. Temperature Sensing. Pt-100 Thermocouples were used for the measurement of temperatures of the cooker as they offer high accuracy and rapid response. Thermocouple junctions were immersed in the water in the pot(s) and placed $10 \mathrm{~mm}$ above the pot bottom, at the centre (illustration of recommended thermocouple mounting). Proper thermocouple placement can minimize errors that might be caused by thermal stratification and sensor intrusion into the pot. The standard tests for solar cooker states that the values of the figure of merits F1 and F2 should be as higher as possible.

$$
F_{1}=\frac{T_{P}-T_{a}}{I_{S}}=\frac{\eta}{U_{L S}},
$$

where $F_{1}=$ figure of merit of solar cooker, $T_{P}=$ plate temperature, $T_{a}=$ ambient temperature, $I_{S}=$ incident solar radiation, $\eta=$ efficiency, and $U_{L S}=$ losses of solar cooker.

Since cookers normally operate near the stagnation temperature, the first figure of merit $F_{1}$ is calculated for both GEDA cooker and Star cooker. The values for $F_{1}$ obtained are 0.0986 meter $^{2}$ kelvin/watt and 0.0552 meter $^{2}$ kelvin/watt, respectively.

This shows that there are some limitations in the performance of the box type solar cookers as the BIS has fixed that SBS should be at least 0.12 meter $^{2}$ kelvin/watt. However, tests conducted on several commercially available solar cookers in Gujarat revealed that the value 0.12 for $F_{1}$ is practically unattainable and suggested that it should be lowered down $[3,4]$.

\section{Conclusion and Future Scope}

The Photo-Thermo solar cooker is not affected by the uncontrolled parameters, namely, wind, ambient temperature, pot contents temperature, insolation, solar altitude, and azimuth angle, and so forth. The indoor cooking reduces the physical strain of the user. The cooker can be used round the clock. It is lighter in weight and smaller in size. So it can be transported easily. It does not contain any mirror or glasses which are the breakable parts in box type solar cooker. This user-friendly Photo-Thermo solar cooker can be commercialized too.

Further, our plan is to replace the power supply by a DC battery of 12 volt 40 ampere hour. It will be charged by a solar panel of 75 watt. Only the panel will be kept either on the terrace or in the balcony of the house. The cooking will be done in the kitchen.

\section{Acknowledgments}

The authors would like to thank Director of SPRERI for availing the radiation data. They also thank Mr. Shreelal Jha and Harshvardhan Jha for instrumental support and engineering drawings.

\section{References}

[1] "International Standard for Testing Solar Cookers ASABE Standard S580 Dr. Paul A. Funk,” Avinashilingam University, Coimbatore, India, January 1997.

[2] S. C. Mullick, T. C. Kandpal, and A. K. Saxena, "Thermal test procedure for box-type solar cookers," Solar Energy, vol. 39, no. 4, pp. 353-360, 1987.

[3] S. K. Philip and H. N. Mistry, "Solar cooker testing: "a suggestion for change in BIS standards'”' SESI Journal, vol. 5, pp. 17-22, 1995.

[4] S. K. Philip, T. K. Chaudhuri, and H. N. Mistry, "Testing of solar box cookers," in Proceedings of the 3rd International Conference on Solar Cookers Use and Technology, Coimbatore, India, 1997. 


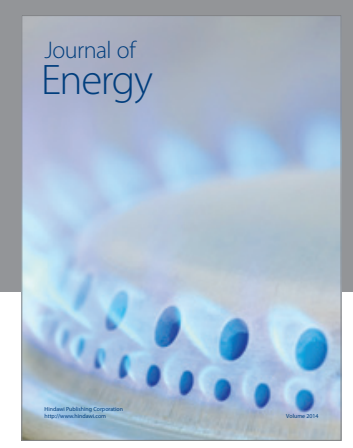

Journal of

Industrial Engineering
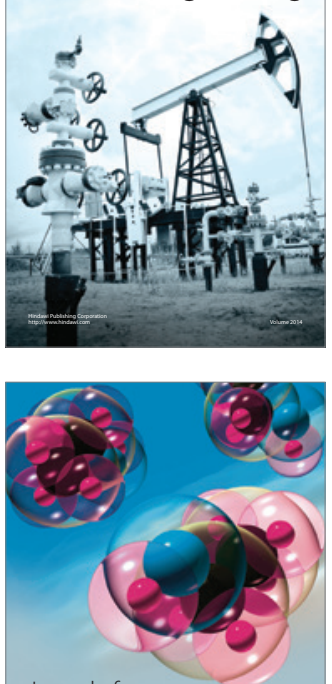

Fuels
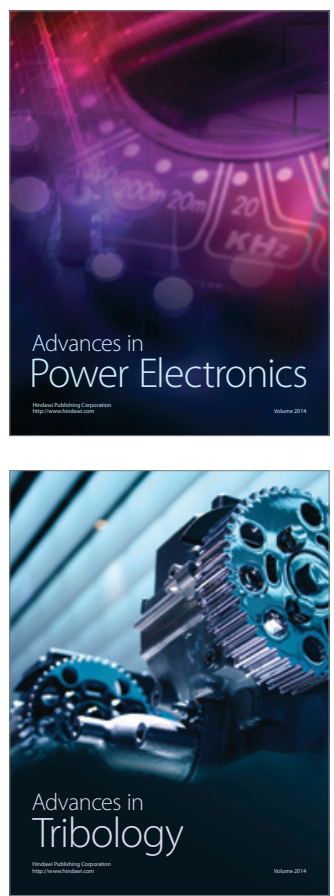

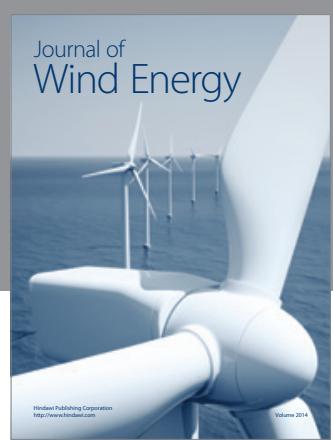

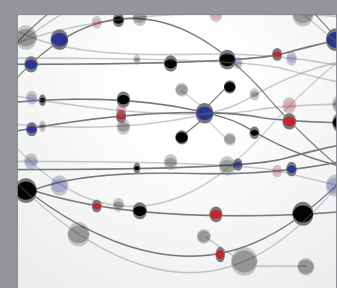

The Scientific World Journal

Submit your manuscripts at http://www.hindawi.com

Journal of

Structures
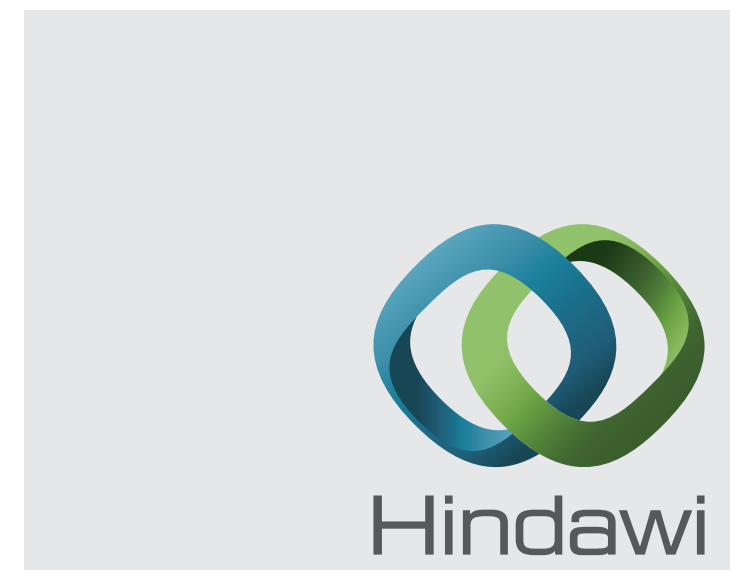

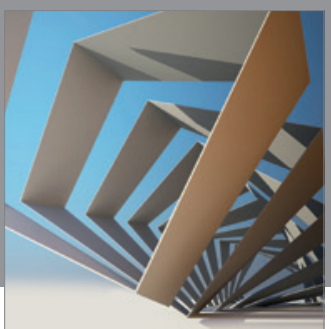

Rotating

Machinery
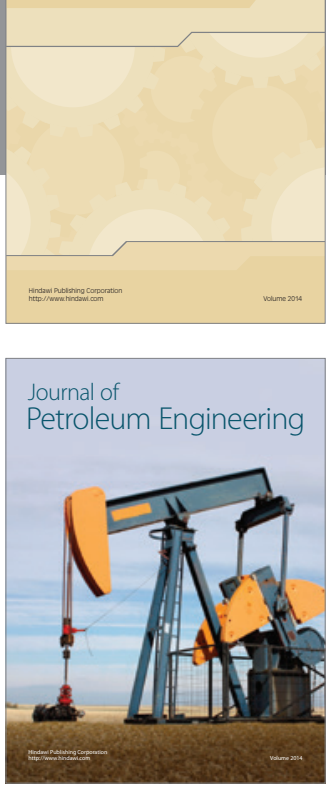

Journal of

Solar Energy
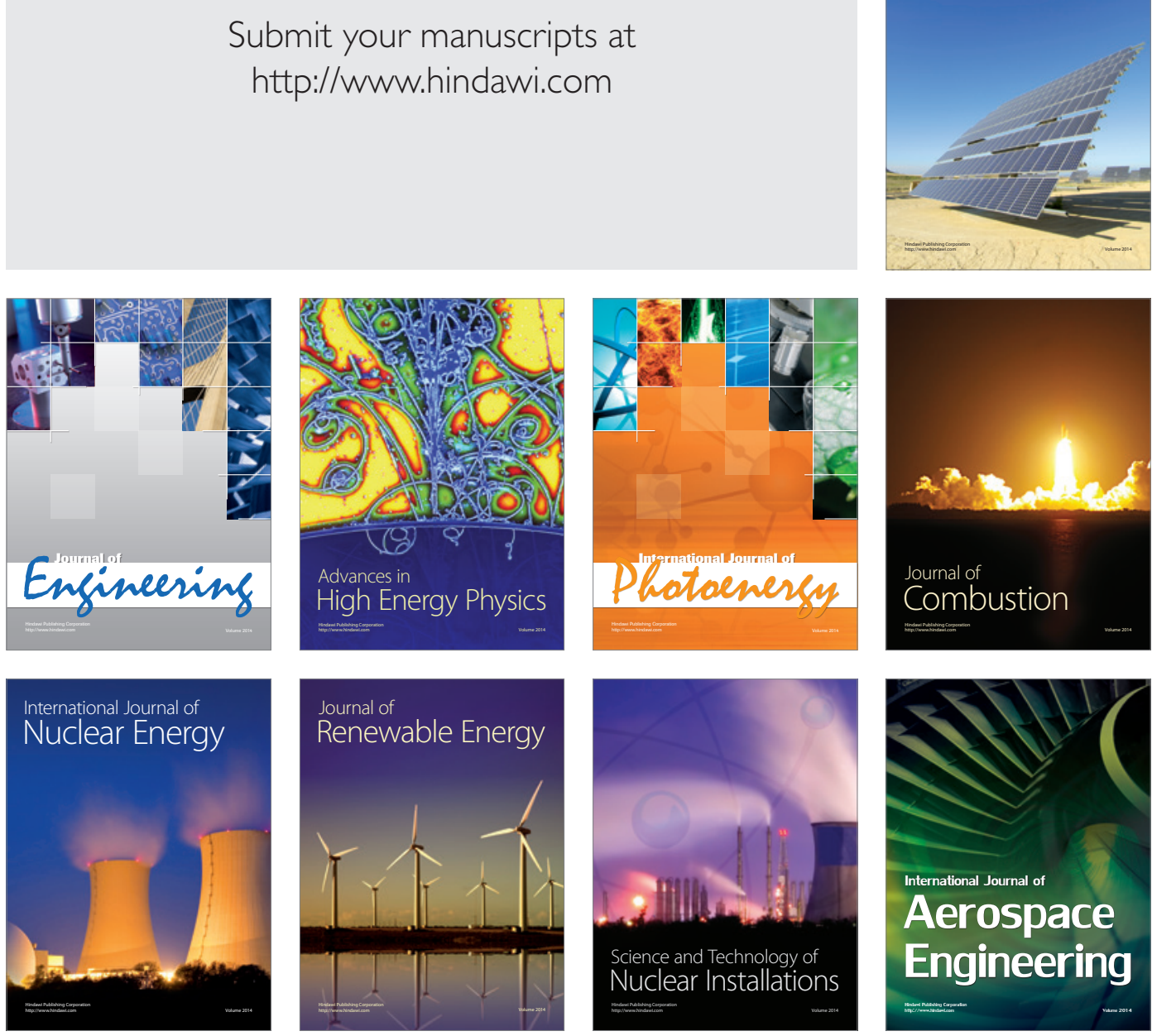